\title{
A Violência Simbólica e e Espaço Escolar
}

\author{
Emídia Inácio Timóteo ${ }^{1}$; Anna Christina Farias de Carvalho ${ }^{2}$
}

Resumo: Fenômeno complexo e multicausal, a violência apresenta conceitos que fogem ao dogmatismo preciso e estruturado, sendo alguns destes contraditórios e/ou divergentes. Entretanto, podemos apontar, diante do processo histórico, que a violência é um fato humano e social e como construção social tem solução ou pelo menos diminuição num patamar menos epidêmico. No Ceará, como de fato na maioria dos Estados brasileiros, as pesquisas sobre violências, especialmente sobre violência simbólica são escassas, quando muitas vezes também inexistem estatísticas acerca do fenômeno. Sob um ponto de vista mais amplo, podemos concluir que as agressões físicas, simbólicas ou patrimoniais infligidas pelos alunos, são reproduzidas no espaço escolar a partir das vivências sociais e familiares.

Palavras-chave: Violência. Espaço escolar. Violência simbólica.

\section{Symbolic Violence and the School Environment}

\begin{abstract}
Phenomenon complex and multifactorial, violence presents concepts that are beyond the precise and structured dogmatism, and some of these contradictory and / or divergent. However, we can point out before the historical process, that violence is a human and social fact and as a social construct has a solution or at least a less decrease epidemic level. In Ceará, as indeed in most Brazilian states, research on violence, especially on symbolic violence are scarce, when also often nonexistent statistics on the phenomenon. From a broader perspective, we can conclude that the physical, symbolic or property assaults inflicted by students, are played at school from social and family experiences.
\end{abstract}

Keywords: Violence. school environment. Symbolic violence.

\footnotetext{
${ }^{1}$ Mestranda em Ciências da Educação pela Universidade Anne Sullyvan.

${ }^{2}$ Doutora em Sociologia pela Universidade Federal da Paraíba - UFPB. Professora Aposentada da Universidade Regional do Cariri -

URCA. Pesquisadora do Núcleo de Estudos em Ciência, Espiritualidade e Filosofia - NECEF/URCA. Atualmente cursando Pós-Doutorado no Programa de Pós-Graduação em Letras da UFPB e exercendo a função de Assessora de Cultura e Extensão na Pró-Reitoria de Extensão da URCA.
} 


\section{Introdução}

Desde os anos oitenta, tem-se intensificado nas sociedades ocidentais inúmeros discursos sobre as causas e consequências da violência. $\mathrm{O}$ fenômeno da violência é interpretado como produto de fatores de ordem pessoal, social e cultural. Desse modo, os vários tipos de violência na sociedade interpenetram-se atingindo todos os tecidos sociais.

Fenômeno complexo e multicausal, a violência apresenta conceitos que fogem ao dogmatismo preciso e estruturado, sendo alguns destes contraditórios e/ou divergentes. Entretanto, podemos apontar, diante do processo histórico, que a violência é um fato humano e social e como construção social tem solução ou pelo menos diminuição num patamar menos epidêmico. Estratégias de enfrentamento da violência foram sugeridas e discutidas no Seminário "O Desafio do Enfrentamento da Violência: situação atual, estratégias e propostas" promovido pelo Conselho Nacional de Secretários de Saúde (CONASS, 2008). As propostas estão indicadas, entretanto a violência aumenta de índice a cada ano, não só no Brasil, como em todo o Planeta. Para além do entendimento e conhecimento acerca das violências, a pergunta é: a partir de quais instrumentos e ações podemos construir uma Cultura de Paz? Dizendo de outra forma, como erradicar esse fenômeno epidemiológico cujo agente(s) permeia $(m)$ todo o tecido social?

Algumas respostas emergem, dentre elas nos aproximamos das análises de Ratton (2014) que nos chama atenção para os seguintes aspectos: o Governo Federal tem atuado de forma pontual em espaços como as periferias das grandes metrópoles, entretanto não construiu de forma efetiva estratégias eficazes para enfrentar e acabar com a criminalidade violenta. Em relação aos Municípios, estes comumente não elaboram políticas públicas de prevenção e os Estados, em sua grande maioria, apontam para estratégias insuficientes e ineficientes. Ratton reforça ainda mais a questão da importância dos municípios como instância primordial no aspecto prevenção quando analisa:

No Brasil, os municípios ainda tem uma enorme dificuldade em pensar na questão da prevenção da violência. Há uma omissão generalizada. Se o poder público vem tomando, nos últimos anos, iniciativas que, ainda que acanhadas, são importantes (do ponto de vista da construção de uma presença do Governo Federal na elaboração 
e no monitoramento das políticas públicas de segurança), ainda é absolutamente tímida a capacidade dos governos municipais de produzir iniciativas contundentes que ultrapassem uma mera retórica de estar fazendo prevenção de forma geral através da saúde, da educação, da assistência social etc. Assim mesmo o poder local, é o mais próximo e o que mais conhece as próprias comunidades, e as respostas - a prevenção - têm um nítido componente contextual e territorial (2012, p. 20).

Autores como Waiselfisz (2014) relatam que estados como o Ceará, Goiás, Bahia, Sergipe, Pará e Paraíba, que em 1998 apresentavam índices relativamente abaixo do índice nacional, em 2012 passaram a fazer parte do ranking dos dez estados mais violentos do país.

Nesse contexto, a proposta de nosso artigo visa contribuir na compreensão e socialização desse fenômeno, através de uma discussão calcada na reflexão, especialmente, da violência simbólica.

Nesse sentido, o conceito de violência que estamos utilizando neste trabalho é amplo, incluindo além do uso de força e/ou intimidação, suas dimensões socioculturais e simbólicas.

Pretendemos com esse texto identificar possíveis atitudes de comportamento, condições sociais, econômicas, políticas e culturais relacionadas às práticas violentas dos sujeitos integrantes do universo escolar, especialmente em relação a violência simbólica.

Sendo a violência fator de forte impacto social, suas causas são algumas vezes visíveis e outras vezes estão tão incrustadas na tessitura social, econômica e cultural do cotidiano, tornando-se quase invisível.

Tais aspectos, acreditamos, são muitas vezes a mola mestra que desencadeia uma série de atos violentos, que por não serem acompanhados da agressão física nem se configurarem como caso de polícia não é considerado ato de violência. Então, vejamos: humilhação constante mais conhecida como bullying, discriminação de raça, gênero, religião; constitui o que o sociólogo francês Pierre Bourdieu conceitua como "violência simbólica", esta é exercida com bastante vigor nas diversas instâncias da sociedade.

As violências simbólica, institucional e física estão no dia a dia da população, o que já justificaria uma intervenção sistemática para seu entendimento e redução. Diante dessa realidade que nos descortina, nosso trabalho se justifica como instrumento de sensibilização e reflexão acerca de um fenômeno que abriga também aspectos culturais e comportamentais, 
sendo sua compreensão um valioso instrumento que certamente auxiliará na transformação social e na implantação de uma Cultura de Paz.

\section{Violência Simbólica: Aspectos Conceituais}

Em termos conceituais vamos utilizar a violência simbólica especialmente através dos estudos de Pierre Bourdieu. Para esse autor, o poder simbólico se estrutura através dos sistemas simbólicos como a arte, a educação, a língua, a religião, entre outras instâncias do social. Tais aspectos do social tem a função de integrar a sociedade através de um consenso acerca da ordem estabelecida.

Nesse contexto, os sistemas simbólicos atuam politicamente sobre o corpo social emergindo como formas de dominação invisíveis que legitimam a ordem social vigente. $\mathrm{O}$ que torna possível a eficácia desse poder é “[...] a cumplicidade daqueles que não querem saber que lhe estão sujeitos ou mesmo que o exercem." (1998, p. 7-8).

De acordo com a perspectiva Bourdieusiana, Souza (2012, p. 2) faz uma interessante análise nesse sentido:

[...] a violência simbólica se expressa na imposição legítima e dissimulada, com a interiorização da cultura dominante e há uma correlação entre as desigualdades sociais e escolares. As posições mais elevadas e prestigiadas dentro do sistema de ensino (definidas em termos de disciplinas, cursos, ramos do ensino, estabelecimentos) tendem a ser ocupadas pelos indivíduos pertencentes aos grupos socialmente dominantes. Por mais que se democratize o acesso ao ensino por meio da escola pública e gratuita, continuará existindo uma forte correlação entre as desigualdades sociais, sobretudo culturais. Essa correlação só pode ser explicada quando se considera que a escola valoriza e exige dos alunos determinadas qualidades que são desigualmente distribuídas entre as classes sociais, notadamente, o capital cultural e certa naturalidade no trato com a cultura e o saber, que apenas aqueles que foram desde a infância socializados na cultura legítima podem ter.

A violência simbólica esta relacionada ao que diz respeito à educação, religião, economia, desigualdade social, racial e isso tudo de forma mascarada. A escola por sua vez é instrumento ideológico do estado, pois passa uma imagem contrária da realidade dos mesmos, a escola ao invés de torna-los seres pensantes, críticos acabam impondo uma visão distorcida, contribuindo assim para uma situação que irá se perpetuar através do habitus: e que "o hábito adquirido na escola esteja no princípio do nível de recepção e do grau de assimilação das 
Id on Line Revista Multidisciplinar e de Psicologia

Id on Line Multidisciplinary Journal and Psycology

mensagens produzidas e difundidas pela indústria cultural” (BOURDIEU ; PASSERON, 1992, p. 54).

De acordo com L’Apiccirela ( 2015, p. 2):

Tomando, como foco principal, a escola pública brasileira, esta ignora a origem de seus alunos, transmitindo-lhes o "ensino padrão". Bourdie e Passeron explicam este processo pela Ação Pedagógica, que perpetua a violência simbólica através de duas dimensões arbitrárias: o conteúdo da mensagem transmitida e o poder que instaura a relação pedagógica exercido por autoritarismo. A autoridade pedagógica que visasse destruir a violência simbólica destruiria a si própria, pois se trata do poder que legitima a violência simbólica.

No Brasil, o conteúdo transmitido nas escolas é aquele que interessa à perpetuação da hegemonia cultural da classe média e alta: a realidade do branco, urbano e bem sucedido é passada como exemplo natural de sucesso; as peculiaridades das culturas regionais são transmitidas a título de curiosidade; quanto às culturas do índio e do negro, indissociáveis do que poderíamos chamar de cultura brasileira, são transmitidas como algo à parte da cultura dominante, tornando-nos alienados quanto à sua presença no nosso cotidiano.

Hoje a criança entra na escola muito cedo, pelo os mais diversos motivos, e a personalidade começa a ser ali construída. A escola tem grande poder no sentido de construir conceitos, porém infelizmente a escola termina não desempenhando seu papel, pois sob a hegemonia da classe dominante, acaba por repassar essa cultura, fortalecendo assim ainda mais o controle da classe dominante, como foi apontado por L`Apiccirella na citação acima.

\section{A Escola Como Espaço De Insegurança?}

O contexto cearense em relação às violências nas Escolas não difere do contexto escolar brasileiro. Como já referimos, o Ceará é uma dos dez Estados com maior índice de violência no país (Waiselfisz, 2014). Sendo um bem público garantido individualmente pela Constituição de 1988 (artigos quinto e sexto), entendemos que o Estado está se tornando incapaz de garantir esse direito, especialmente na Instituição Escolar, lugar anteriormente considerado espaço de socialização e segurança. 
A violência escolar está se tornando um problema de dimensões incalculáveis. Toda a comunidade escolar a ela está sujeito, de gestores a professores, alunos e funcionários, todos estão cotidianamente sob sua mercê. A violência patrimonial também se apresenta com a depredação do patrimônio publico, se estende também aos pais e a comunidade como um todo. Segundo Sarmento et al (2009, p. 37):

\begin{abstract}
A violência presente na sociedade, na família e no bairro também se manifesta e abala fortemente as instituições escolares. Mas, é na escola, sobretudo, por meio dos alunos e professores, que a violência vem sendo materializada de forma emblemática durante as atividades curriculares, na difícil relação entre alunos e/ou professores/gestores. Muitas manifestações de violência que ocorrem no interior das escolas são reflexos da própria violência instalada no meio social - bairros periféricos e violentos, desprovidos de políticas sociais - onde a exclusão social, cultural e política se manifesta de modo mais acentuada. A escola, portanto, inserida neste contexto, não estaria imune a atos de vandalismo, arrombamentos, ameaças, depredações, invasões, roubos, agressões físicas e verbais, incivilidades, hostilidades, indisciplina, transgressões, entre tantos outros adjetivos que caracterizam a violência.
\end{abstract}

A violência escolar, conforme referido, não se materializa apenas na expressão física, mas está também associada a violência simbólica, especialmente através de ameaças, xingamentos, humilhações entre outros. Tal fato acontece entre alunos; entre alunos e professores, gestores e funcionários, podendo evoluir para agressão física e morte.

No Ceará, como na maioria dos Estados brasileiros, as notícias de violência escolar só se evidenciam quando há agressões físicas ou morte, os casos de violência simbólica não atraem o interesse do público em geral, portanto também da mídia.

E a violência simbólica? Ora, se não temos estatísticas, nem muitos estudos sobre a violência física no Ceará, imagine em que ponto está a violência "invisível”. Segundo Gomes (2012), as pesquisas acerca de uma das mais comentadas das violências simbólicas - o bullying - ainda são escassas "resultando num atraso de mais de 15 anos em relação à Europa", além do desconhecimento por parte de muitos pesquisadores brasileiros acerca da conceituação do fenômeno e sua incidência, que estaria "dentro da média mundial” (2012, p. 01). Acentua Gomes (IDEM):

Nem banalização nem exageros. Em razão do desconhecimento do seu conceito, a inserção da definição do bullying (intimidação vexatória) no projeto do novo Código 
Penal levou muita gente a supor que se tratasse de uma neocriminalização própria (criação de um novo injusto penal). Na verdade, tudo que se pratica no bullying (xingamentos, ofensas, ameaças, constrangimentos, lesões etc.) já está tipificado nas leis penais. Trata-se, portanto, de uma neocriminalização imprópria, que pode ser útil para difundir a exata dimensão do conceito assim como facilitar a sua sistematização. De qualquer modo, mesmo que esteja tal definição no Código Penal, não se pode imaginar que é com ela que vamos enfrentar adequadamente e prevenir o fenômeno. De outro lado, somente os casos muito graves é que devem ser levados para o âmbito do controle formal. Todos os mecanismos de contenção do bullying já desenvolvidos e praticados na esfera escolar, a começar pelo diálogo, mediação, conciliação etc., tudo isso não vai deixar de ter incidência. Somente os casos realmente muito graves, de ofensas intoleráveis, é que deveriam ingressar no sistema formal de controle.

Nesse contexto, podemos inferir que a escola não cumpre seu papel primordial que é a libertação e aqui fazemos uma referência ao célebre educador Paulo Freire, que em suas análises e como projeto de vida lutou por uma educação libertadora, em defesa da função da escola como matriz para transmitir ao educando conhecimentos para que ele pudesse "ler o mundo" para transformá-lo.

\section{Considerações Finais}

Nas sociedades capitalistas, a escola é uma instituição que exerce função de reprodução das ideias da classe dominante;

O conceito de violência simbólica, foco principal de nosso artigo, tem sua base teórico nas análises de Bordieu e Passeron;

Sob um ponto de vista mais amplo, podemos concluir que as agressões físicas, simbólicas ou patrimoniais infligidas pelos alunos, são reproduzidas no espaço escolar a partir das vivências sociais e familiares;

No Ceará, como de fato na maioria dos Estados brasileiros, as pesquisas sobre violências, especialmente sobre violência simbólica são escassas, quando muitas vezes também inexistem estatísticas acerca do fenômeno;

Apesar de implantar projetos e programas para o enfrentamento das violências, o Estado brasileiro, em suas três esferas, é ineficaz para diminuir ou erradicar o problema. 
Id on Line Revista Multidisciplinar e de Psicologia

Id on Line Multidisciplinary Journal and Psycology

\section{Referências}

BOURDIEU, Pierre. O poder simbólico. Rio de Janeiro: Bertrand, 1998.

BOURDIEU, Pierre; PASSERON, Jean Claude. A reprodução: elementos para uma teoria do sistema de ensino. 3. ed., Rio de Janeiro: Francisco Alves, 1992.

CONASS. O desafio do enfrentamento da violência situação atual, estratégias e propostas, 2008

$\langle$ http://bvsms.saude.gov.br/bvs/publicacoes/desafio_enfrentamento_violencia.pdf $>\quad$ Acesso em 10 set. 2015.

GOMES, Lúcio Flávio. Brasil: escassez de estudos e a deturpação do conceito de bullying, 2012. Disponível em: http://institutoavantebrasil.com.br/brasil-escassez-de-estudos-e-adeturpacao-do-conceito-de-bullying Acesso em: 20 set. 2015

L’APICCIRELLA, Nadine. O papel da educação na legitimação da violência simbólica. IN: Revista Eletrônica de Ciências. N. 20, jul. 2003.

RATTON, José Luiz. Apresentação seminário políticas locais de prevenção da violência. In: A segurança cidadã em debate. Recife:Provisual, 2012. v. 3, p. 11-23.

SARMENTO, Hélder Boska de Moraes; PAIXÃO, Carlos Jorge; NUNES, Cely do Socorro Costa Violência e ética no cotidiano das escolas.Belém: Unama, 2009.

SOUZA, Liliane Pereira de. A violência simbólica na escola: contribuições de sociólogos franceses ao fenômeno da violência escolar brasileira. IN: Revista LABOR n.7, v.1, 2012.

WAISELFISZ, Julio Jacob. Mapa da violência 2014: os jovens do Brasil. Brasília:Secretaria Geral da Presidência da República;Secretaria Nacional de Juventude, 2014.

Como citar este artigo (Formato ABNT):

TIMÓTEO, E.I.; CARVALHO, A.C.F. A Violência simbólica e o espaço escolar. Id on Line Revista Multidisciplinar e de Psicologia, Set-Out de 2016, vol.10, n.31, Supl 2, p. 194-201. ISSN 1981-1179. 